\title{
Study and Analysis of the Effective Geometries for the Piezoresistive Pressure Sensors
}

\author{
S.Suganthi*1, V.S.Selvakumar ${ }^{1}$,A.Asha ${ }^{1}$, N Shivaanivarsha ${ }^{2}$, Senthilkumar $^{2}$, L.Sujath ${ }^{3}$ \\ ${ }^{1}$ Associate Professor, Department of Electronics and Communication Engineering \\ Rajalakshmi Engineering College, Chennai \\ ${ }^{2}$ Associate Professor, Department of Electronics and Communication Engineering \\ Sairam Engineering College, Chennai \\ ${ }^{2}$ Associate Professor, Department of Electronics and Communication Engineering \\ Rajalakshmi Institute of technology, Chennai \\ ${ }^{3}$ Professor, Department of Electronics and Communication Engineering \\ Rajalakshmi Engineering College, Chennai
}

Article History:Received:11 november 2020; Accepted: 27 December 2020; Published online: 05 April 2021

\begin{abstract}
THE REPORTED WORK IS ON THE DESIGN AND SIMULATION OF MICROELECTROMECHANICAL SYSTEMS (MEMS) BASED SILICON PIEZORESISTIVE PRESSURE SENSOR DEPLOYED TOSENSE PRESSURE IN THE RANGE OF 0 TO 1.1 BAR. THE PRESSURE IS APPLIED ON THE DIAPHRAGM CONSISTING OF FOUR PIEZORESISTORS CONNECTED IN THE WHEATSTONE BRIDGE CONFIGURATION. THE INDUCED STRESS AS A RESULT OF THE PRESSURE CAUSES CHANGE IN RESISTANCE OF PIEZORESISTORS DUE TO PIEZORESISTIVE EFFECT. THE DESIGN AND SIMULATION OF THE SENSORS PRIOR TO FABRICATION HELPS US TO OPTIMIZE THE DIAPHRAGM THICKNESS AND SIZE. MEANDER SHAPED PIEZORESISTORS WITH DIFFERENT NUMBER OF TURNS ARE STUDIED IN ORDER TO FIND OUT THE BEST CONFIGURATION FOR HIGH SENSITIVITY AND LINEARITY. THE DESIGN AND SIMULATION IS CARRIED OUT USING FEM (FINITE ELEMENT METHOD) BASED COMSOLMUlTIPHYSICS. BASED ON THE SIMULATION RESULTS, THE TWO-TURN CONFIGURATION IS FOUND TO HAVE THE BEST SENSITIVITY OF 4.181 MV/V/BAR AND THE ONE TURN CONFIGURATION GIVES THE LEAST NON-LINEARITY OF $0.5051 \%$
\end{abstract}

Keywords: MicroElectroMechanical Systems; Piezoresistivity; Pressure sensor; Finite element method.

\section{INTRODUCTION}

Pressure sensing has become an integral part of various applications such as chemical processing, biomedical instrumentation, automotive industry, aviation engineering, oil fields, industrial measurement and control system [1]. MEMS based pressure sensors have replaced the traditional pressure sensors because of their small size and enhanced sensor characteristics. There are various sensing principles which can be employed for measurement of pressure namely piezoresistive, capacitive, resonant and piezoelectric sensing [2]. Out of these different sensing principles, the piezoresistive sensing is preferred in pressure sensors because of ease of fabrication, high reliability, high linearity in output of sensor and simple compensation circuitry [3].

Piezo resistance is the phenomenon of change in resistivity of certain materials (like silicon, polysilicon, $\mathrm{SiC}$ etc.) on application of stress/strain. Piezoresistive pressure sensors employ this principle to measure the applied pressure. Piezoresistive sensors also have much higher sensitivity than the metal strain gauges which work on the basis of change in resistance due to geometrical deformation[4]. Pressure sensors for barometric applications constitute an important part of pressure sensor market. These types of sensors are used to measure the ambient atmospheric pressure and are generally used in weather forecasting, altimeters and in aviation sector.

Piezoresistive pressure sensors employing the use of silicon as a piezoresistive element are very popular due to advantages like high sensitivity and repeatability of output [5]. Polysilicon based pressure sensors have the advantage in high temperature applications due to the presence of an insulating layer under the sensing polysilicon piezoresistors.[6,7,8] But these sensors have the disadvantage of low sensitivity and difficulty in controlling the characteristics of polysilicon. Pressure sensors employing the use of other materials like $\mathrm{SiC}$ and diamond for piezoresistors are not very popular for commercial usage because the fabrication technology is not mature for such materials. $[9,10,11,12]$ Also, silicon based piezoresistors can be easily fabricated using ion implantation where in the sheet resistance of the resistors can also be carefully controlled.[13,14] In this work, we will discuss the design and simulation of a piezoresistive pressure sensor based on piezoresistance in silicon. This paper is organized as follows. First, we describe the working of a silicon piezoresistive pressure sensor. This is followed by the specifications and design parameters of a barometric pressure sensor, based on different

*Corresponding author: S.Suganthi

Associate Professor, Department of Electronics and Communication Engineering

Rajalakshmi Engineering College, Chennai 
design and fabrication considerations. Finally, we give the results of simulation of various designs of pressure sensor using COMSOL.

\section{SILICON PIEZORESISTIVE PRESSURE SENSOR}

A piezoresistive pressure sensor consists of a diaphragm with four piezoresistors on top of it connected in a Wheatstone bridge arrangement. The diaphragm is generally formed by dry etching using Deep Reactive Ion Etching (DRIE) or though wet bulk micromachining using alkali hydroxides like Potassium hydroxide (KOH) or Tetramethylammonium hydroxide (TMAH). The diaphragm is sealed from back side using anodic bonding in vacuum in order to measure the absolute value of pressure. The applied pressure causes diaphragm deflection and stress in diaphragm, which is sensed by the piezoresistors on top of the diaphragm. The piezoresistors are placed in regions of diaphragm where high stress is generated when a pressure is applied. The size, shape and thickness of the diaphragm and the shape and placement of piezoresistors are important factors which affect the output of the pressure sensor. Sensitivity and linearity of pressure sensors are the two most important specifications of a pressure sensor and these must be optimized before fabrication.

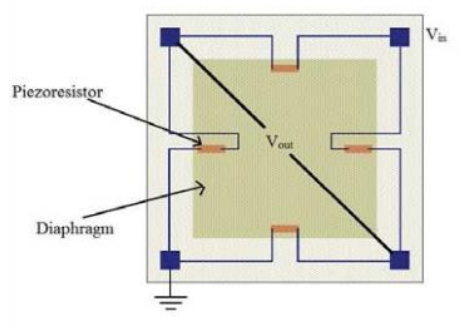

TOP VIEW
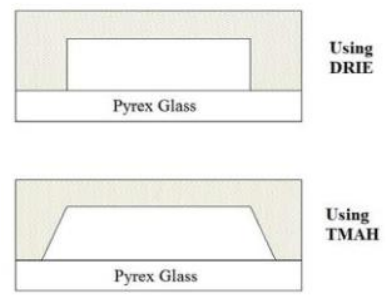

CROSS SECTIONAL VIEW

Fig1. Arrangement of piezoresistors in wheat stone bridge configuration

The change in resistance of a piezoresistive material under stress in given by

$$
\frac{\Delta R}{R}=\frac{\Delta l}{l}-\frac{\Delta A}{A}+\frac{\Delta \rho}{\rho}
$$

The first two terms correspond to geometrical deformation in length and cross section of the resistors, respectively. For piezoresistors under stress, these terms are negligible compared to the last term, which corresponds to change in resistivity. Hence, the equation reduces to,

$$
\text { I. } \quad \frac{\Delta R}{R}=\frac{\Delta \rho}{\rho}=\pi_{1} \sigma_{1+} \pi_{\mathrm{T}} \sigma_{\mathrm{T}}
$$

Where, $\pi_{1}$ and $\pi_{\mathrm{t}}$ correspond to longitudinal and transverse piezoresistive coefficients. $\sigma_{1}$ and $\sigma_{\mathrm{t}}$ are the longitudinal and transverse stresses acting on the piezoresistor. In the present design, the piezoresistors are oriented along [110] directions on (100) wafer in order to maximize the piezoresistive effect. For this orientation,

$$
\pi_{1,110}=\frac{1}{2}\left(\pi_{11}+\pi_{12}-\pi_{44}\right)
$$

Where, $\pi_{11}, \pi_{12}$ and $\pi_{44}$ are the three independent nonzero piezoresistive coefficients of silicon. Two piezoresistors are subjected to longitudinal stress and their resistance increases whereas the other two resistors are subject to transverse stress and their resistance decreases. Thus, the balanced Wheatstone bridge becomes unbalanced and the sensor gives a voltage output.

\section{A Piezoresistive pressure sensor}

\section{A. IV. DESIGN CONSIDERATIONS FOR A PRESSURE SENSOR}

The typical pressure range of operation for such sensors is from 0 to 1.1 bar pressure. After estimating the pressure, the graph between pressure measured and altitude can give the estimate of altitude. Therefore, we will choose this pressure range for our design. The sections below will provide a discussion on the various design considerations and we will finalize the design parameters which would be used for simulations using COMSOL Multiphysics. Pressure sensors demand high linearity of output. Piezoresistive pressure sensors have the 
advantage of better linearity than capacitive pressure sensor. Therefore, we will be using piezoresistive pressure sensing in our design. Ion implantation has been chosen as the technology for fabrication of the piezoresistors because of better deflection theory for bending of thin plates assumes that the deflection of midpoint of surface of diaphragm chosen for simplicity, so that sufficient area is present for TMAH etching from the back side the diaphragm.

Results of simulation of diaphragm size vs. max displacement

\begin{tabular}{|l|l|l|l|}
\hline $\begin{array}{l}\text { Chip Size } \\
\left(\boldsymbol{\mu m}^{2}\right)\end{array}$ & $\begin{array}{l}\text { Diaphragm } \\
\text { Thickness } \\
(\boldsymbol{\mu m})\end{array}$ & $\begin{array}{l}\text { Diaphragm } \\
\text { Size } \\
\left(\boldsymbol{\mu \mathbf { m } ^ { 2 } )}\right.\end{array}$ & $\begin{array}{l}\text { Maximum } \\
\text { Displacement } \\
(\boldsymbol{\mu m})\end{array}$ \\
\hline $4000 * 4000$ & 25 & $1200 * 1200$ & 0.821 \\
\hline $4000 * 4000$ & 25 & $1400 * 1400$ & 1.717 \\
\hline $4000 * 4000$ & 25 & $1600 * 1600$ & 2.82 \\
\hline $4000 * 4000$ & 25 & $1800 * 1800$ & 4.55 \\
\hline $4000 * 4000$ & 25 & $2000 * 2000$ & 8.76 \\
\hline
\end{tabular}

The total resistance of each piezoresistors is taken as $2 \mathrm{k} \Omega$. The piezoresistors would be fabricated by ion implantation of silicon. P-type piezoresistors would be used as they give better sensitivity than n-type piezoresistors. The effect of implanting boron atoms with a dosage of $1.1 \times 10^{15}$ atoms $/ \mathrm{cm}^{2}$ and energy of 80 $\mathrm{keV}$ on n-type substrate with resistivity $5 \Omega$-cm is simulated using Silvaco Athena ${ }^{\circledR}$. This gives a sheet resistivity of $100 \Omega / \mathrm{Sq}$ for the piezoresistors. To obtain a total resistance of $2 \mathrm{k} \Omega$ we would require 20 squares in each resistor. The resistor width is chosen to be $15 \mu \mathrm{m}$ and therefore the length of the resistors comes out to be $15 \times 20=300 \mu \mathrm{m}$. For simplicity, the thickness of the resistors is assumed to be $1 \mu \mathrm{m}$. Therefore, the resistivity of the resistors is $10^{-4} \Omega-\mathrm{cm}$.

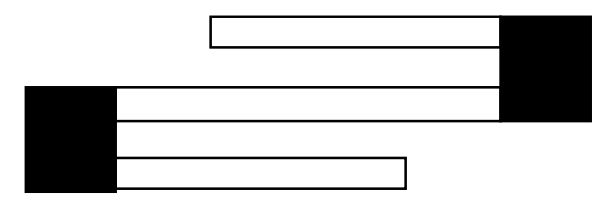

Fig.2.A typical meander shaped piezoresistor

\begin{tabular}{|l|l|}
\hline Structure & Length $(\mu \mathrm{m})$ \\
\hline L & 1800 \\
\hline L0 (No turn) & 300 \\
\hline L1 (One turn) & 150 \\
\hline L2 (Two turns) & 100 \\
\hline L3 (Three turns) & 75 \\
\hline
\end{tabular}

Table 1. Dimensions of the Piezoresistor 


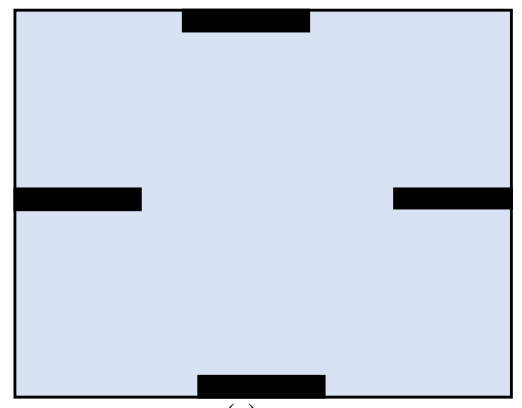

(a)

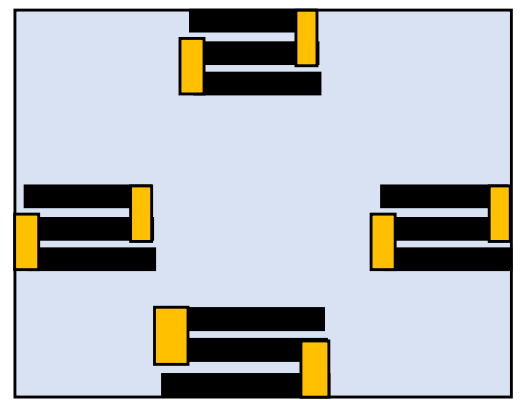

(c)

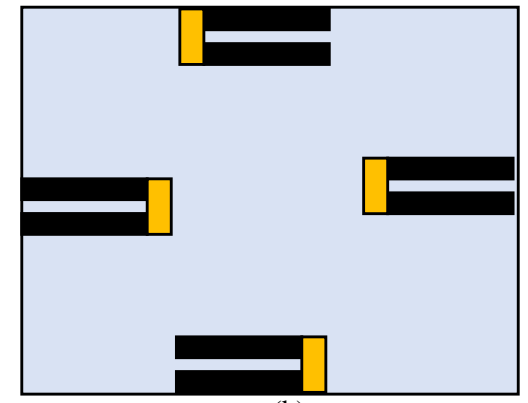

(b)

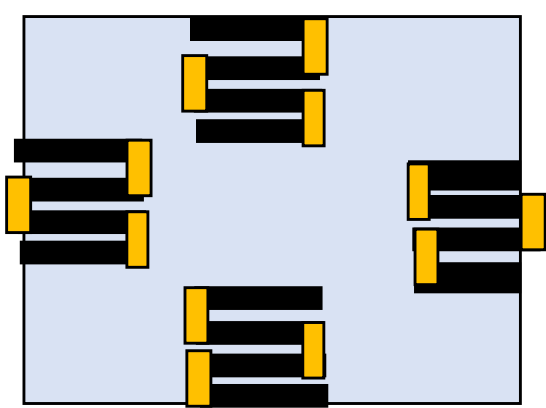

(d)

Fig.3. Design and Structure of the piezoresistive elements (a) No turn, (b) One turn, (c) Two turn, (d) Three turn.

The total length of the piezoresistor arms must be equal to $300 \mu \mathrm{m}$ i.e. this length has to be distributed between the various arms of the piezoresistors. The connecting arms may be formed either using metal lines or using highly doped regions so that they do not contribute to the piezoresistive effect. In our simulations, we would consider four resistor configurations consisting of zero, one, two and diaphragm and length of resistor arms as depicted in three turns.

The total length of the piezoresistor arms must be equal to $300 \mu \mathrm{m}$ i.e. this length has to be distributed between the various arms of the piezoresistors. The connecting arms may be formed either using metal lines or using highly doped regions so that they do not contribute to the piezoresistive effect. In our simulations, we would consider four resistor configurations consisting of zero, one, two and diaphragm and length of resistor arms as depicted in three turns. The total length of the piezoresistor arms must be equal to $300 \mu \mathrm{m}$ i.e. this length has to be distributed between the various arms of the piezoresistors. The connecting arms may be formed either using metal lines or using highly doped regions so that they do not contribute to the piezoresistive effect. In our simulations, we would consider four resistor configurations consisting of zero, one, two and diaphragm and length of resistor arms as depicted in three turns.

\section{Vl. DESIGN SIMULATION USING COMSOL}

The FEA Simulation Package, namely the Silicon structural properties Usually, silicon is considered as an isotropic material for easy analysis and calculations. But in this design, we have used the orthotropic properties of silicon (as given below) for obtaining better accuracy in results.

- Young's modulus $\left(\mathrm{E}_{\mathrm{x}}=\mathrm{E}_{\mathrm{y}}=169 \mathrm{GPa}, \mathrm{E}_{\mathrm{z}}=130 \mathrm{GPa}\right)$

- Young's modulus $\left(\mathrm{E}_{\mathrm{x}}=\mathrm{E}_{\mathrm{y}}=169 \mathrm{GPa}, \mathrm{E}_{\mathrm{z}}=130 \mathrm{GPa}\right)$

- Poisson's ratio $\left(\mathrm{PR}_{\mathrm{yz}}=0.36, \mathrm{PR}_{\mathrm{xy}}=0.064, \mathrm{PR}_{\mathrm{xz}}=0.28\right)$

- $\quad$ Shear modulus $\left(\mathrm{G}_{\mathrm{yz}}=\mathrm{G}_{\mathrm{xz}}=79.6 \mathrm{GPa}, \mathrm{G}_{\mathrm{xy}}=50.9 \mathrm{GPa}\right)$

COMSOL Multiphysics is one such tool. It is a powerfulinteractive environment for modeling and solving all kinds of scientific and engineering problems. It provides a powerful integrated desktop environment with a model builder where one can get full overview of the model and all its functionality. It allows us to extend conventional models of one type into Multiphysics models that solve coupled physics phenomena and do so 
simultaneously. No in-depth knowledge of mathematics or numerical analysis is required. Here, it is possible to build modules by defining the relevant physical quantities such as material properties, loads, source etc. rather than the underlying equations. COMSOL Multiphysics internally compiles a set of equations representing the model. Using the built-in physics interfaces, various types of studies such as stationary and time dependent, linear and non-linear, Eigen frequency, modal and frequency response studies can be performed.

\section{VIl. SIMULATIONRESULTSAND DISCUSSION}

The structure obtained after optimization of various parameters and dimensions is simulated for different values of pressures from 0 to 1.1 bar and the Pressure Vs Displacement is measured. The simulation shows some small output even at zero pressure due to limitation of mesh size that was used for simulation. The combined plot of displacement vs. pressure for all the four piezoresistor configurations. The following results are the various turns forpressure sensor.

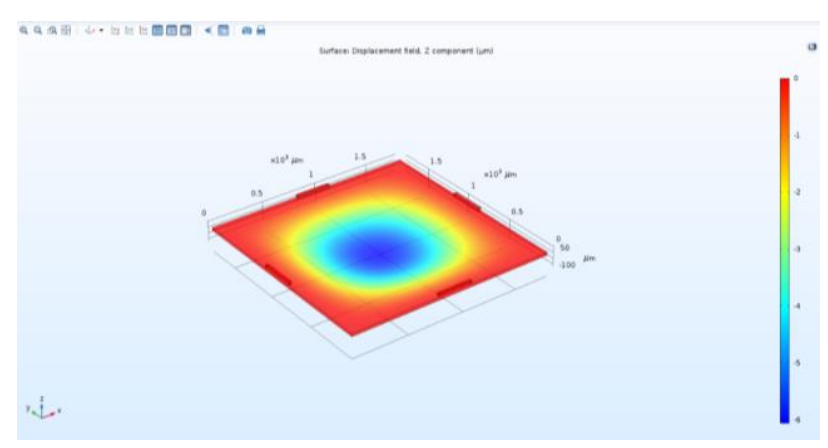

Fig 4 Pressure sensor (No turn)

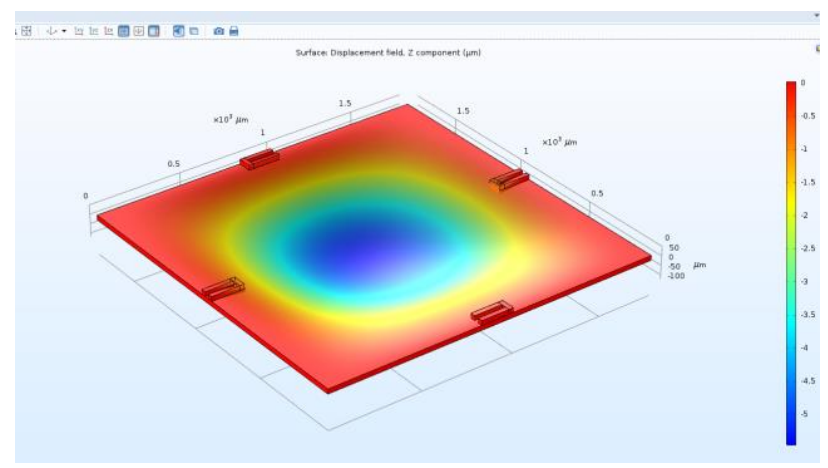

Fig 5.Pressure Sensor (One turn)

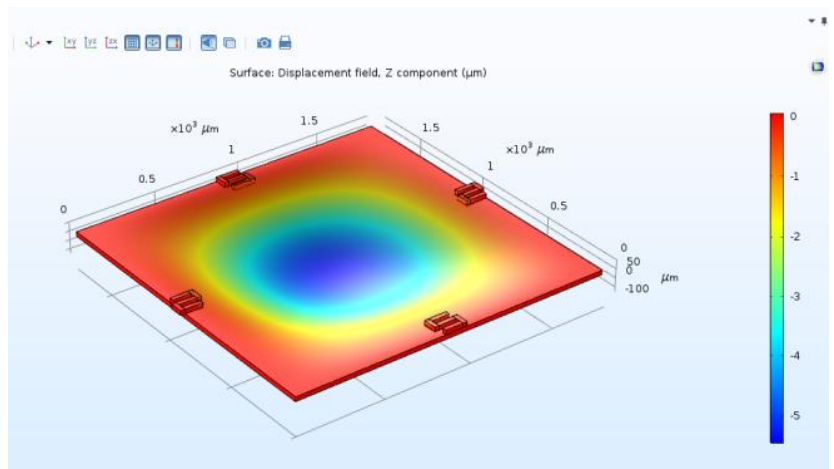

Fig 6. Pressure sensor (Two turn) 


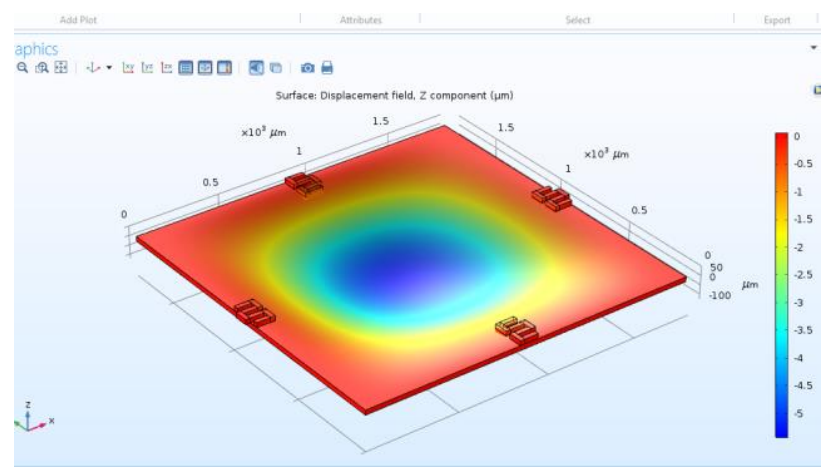

Fig 7. Pressure sensor (Three turn)

The change in displacement is simulated for different values of pressures from 0 to 1 bar. From the table 5.1 we observe that the three turn pressure is found to be the best among all because of its wide range ofdisplacement values.

Table 5.1 PRESSURE Vs DISPLACEMENT

\begin{tabular}{|c|c|c|c|c|}
\hline PRESSURE(MPa) & NO TURN & ONE TURN & TWO TURN & THREE TURN \\
\hline 0.1 & 0.508 & 0.649 & 1.269 & 1.984 \\
\hline 0.2 & 1.016 & 1.265 & 1.856 & 2.526 \\
\hline 0.3 & 1.523 & 1.878 & 2.204 & 2.956 \\
\hline 0.4 & 2.031 & 2.302 & 2.584 & 3.421 \\
\hline 0.5 & 2.539 & 2.852 & 3.475 & 3.951 \\
\hline 0.6 & 3.047 & 3.214 & 4.257 & 4.456 \\
\hline 0.7 & 3.555 & 3.864 & 4.987 & 5.664 \\
\hline 0.9 & 4.063 & 4.356 & 5.324 & 5.865 \\
\hline 1 & 4.571 & 4.869 & 5.554 & 6.309 \\
\hline
\end{tabular}

The output graph for Pressure Vs. Displacement is shown below,

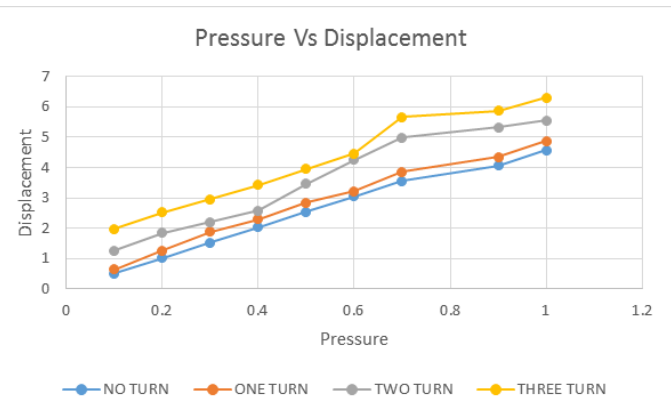

Fig.8. The output graph for Pressure vs. Displacement

\subsection{CONCLUSION}

Through this work, a complete design methodology has been established for silicon piezoresistive barometric pressure sensor for the range of 0 to 1.1 bar. The design principles and flow discussed here can be generalized for design of other pressure sensors having different fabrication technology and/or shape and size of different elements of the sensor. 


\section{References}

S. Guo, H. Eriksen, K. Childress, A. Fink, M. Hoffman, High temperature smart-cut SOI pressure sensor, Sens. Actuators A. 154 (2009) 255.

L. B. Zhao, Y. L. Zhao, Z. D. Jiang, Design and Fabrication of a Piezoresistive Pressure Sensor for Ultra High Temperature Environment, J. Phys. Conf. Ser. 48 (2006) 178.

H. H. Tsai, C. C. Hsieh, C. W. Fan, Y. C. Chen, W. T. Wu, Design and characterization of temperaturerobust piezoresistive micro-pressure sensor with Double-Wheatstone-bridge structure, Symposium on Design, Test, Integration \& Packaging of MEMS/MOEMS. (2009) 363.

Y. H. Zhang, C. Yang, Z. H. Zhang, H. W. Lin, L. T. Liu, T. L.Ren, A Novel Pressure

Microsensor With 30- $\mu$ m-Thick Diaphragm and Meander-Shaped Piezoresistors Partially Distributed on High-Stress Bulk Silicon Region, IEEE Sensors Journal. 7 (2007) 1742.

A. Barlian, W.-T. Park, J. R. Mallon, Jr., A. J. Rastegar, B. L. Pruitt, Review: Semiconductor piezoresistance for microsystems, Proc. IEEE. 97 (2009) 513.

M. Bao, Analysis and Design Principles of MEMS Devices, Elsevier, 2005.

A. L. Herrera-May et al, Electromechanical analysis of a piezoresistive pressure micro-sensor for lowpressure biomedical applications, Revista mexicana de física. 55 (2009) 14.

M. A. Hopcroft, W. D. Nix, T. W. Kenny, What is the Young's modulus of silicon, J. Microelectromechanic. Syst. 19 (2010) 229.

S.Suganthi, L.Sujatha , V.S.Selvakumar , P.Rajasekar, K.Karthikeyan "Fabrication and Study of OnChip Electrode for Capacitive Type Uric Acid Sensor" Solid State Technology 63 (5), 40194027,2020 .

Suganthi Selvakumar, Sujatha Lakshminarayanan, Rajasekar Panchamurthy 2017, 'Functionalized Poly Dimethyl Siloxane Layer for Capacitive Type Uric Acid Sensor' vol. 15, pp. 242-248, Sensor Letters, American Scientific Publishers 2017

V. S. Selvakumar, S. Suganthi, L. Sujatha, and C. V. Gayathri "Microfabrication and Evaluation of a Novel MEMS Based Polysilicon Microheater for Microfluidic Applications” vol. 17, 1-7, 2019 Sensor Letters, American Scientific Publishers 2019.

C.V. Gayathri L. Sujatha, V. S. Selvakumar, S. Suganthi, “A NOVEL MEMS BASED MICROHEATER FOR GAS SENSING APPLICATIONS USING COMSOL" World Journal of Engineering and Technology, Volume 5, Issue 2, Pages 304-314.

V. S. Selvakumar,L.Sujatha,S.Suganthi, "Fabrication of Nanoparticles Based Nanoporous Silicon Sensor for Detection of Volatile Organic Compounds", Sensor Letters 17 (No 6), Pg:423-430, 2019 


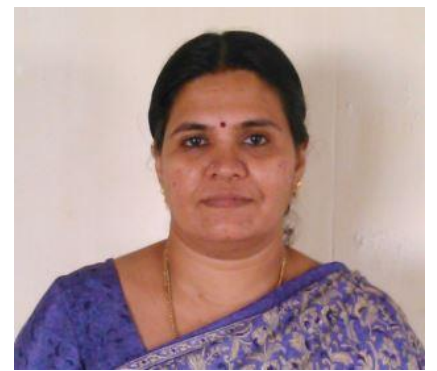

Dr.S.Suganthi , Associate Professor, dept. of ECE, Rajalakshmi Engineering College, Chennai, India has been serving this institution since June 2008. She has completed her Ph.D. during April 2019 in the field of MEMS Biosensor at CEMM, REC. She had carried out the fabrication, study and analysis of microfluidic sensing device for uric acid. She started her career in teaching in 1996 after completing her B.E. ECE in 1995 and then completed M.E. in Applied Electronics from SSN College in 2006. She has 17 years of teaching and 10 years of research experience. Her research work was funded by University Grants Commission. She has also presented the work in the $43^{\text {rd }}$ International Conference on Micro and Nano engineering (MNE 2017), held at Braga, Portugal, during 18th to 22nd September 2017. She has guided several students at the UG and PG level in the field of MEMS.

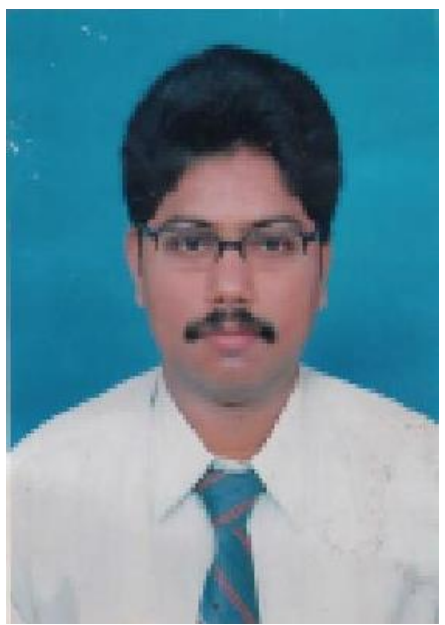

Mr.V.S.V.S.Selvakumar Associate Professor, dept. of ECE, Rajalakshmi Engineering College, and Chennai, India has been serving this institution since June 2007. he has submitted his Ph.D. thesis at April 2020 in the field of MEMS gas sensor at CEMM, REC. he had carried out the fabrication, study and analysis of PS based gas sensor for detection of Alcohol .As my interest in these areas developed, and also based on my past research experience, I would like to see new opportunities in recent developments in the Micro and Nano world. Apart from my research experience, I have also contributed as a teacher (21 years) my service to the Academic courses in the Department of Electronics \& Communication Engineering of various engineering colleges. I have obtained my master's degree from Sathyabama University and went on to pursue my Ph.D. at Anna University in the field of Micro Electro Mechanical Systems (MEMS). I have published 19 journal papers and 27 conferences' publications. I presented my work titled "Design Analysis and characterization of Porous Silicon based gas sensor" at an International Conference held at Malaysia in February 2018 and won the Excellent Paper Award. 